\title{
A Critical Appraisal of Kurjak Antenatal Neurodevelopmental Test: Five Years of Wide Clinical Use
}

Asim Kurjak ${ }^{1}$, Milan Stanojević ${ }^{2}$, Lara Spalldi Barišić ${ }^{3}$, Panos Antsaklis ${ }^{4}$, Raul Moreira Neto ${ }^{5}$, Suada Tinjić ${ }^{6}$, Sonal Panchal $^{7}$, Dorota Bomba Opon ${ }^{8}$, Gigi Selvan ${ }^{9}$, Sertac Esin ${ }^{10}$, Edin Medjedovićc ${ }^{11}$, Aida Salihagić Kadić ${ }^{12}$, Selma Porović ${ }^{13}$, Miro Jakovljević ${ }^{14}$

\begin{abstract}
Purpose: To evaluate the results of the Kurjak antenatal neurodevelopmental test (KANET) in multicentric studies.

Materials and methods: In KANET, normal, borderline, and abnormal fetuses postnatal development was followed. The Chi-square was considered significant if $p<0.05$ was used in the statistical analysis. Specificity, sensitivity, prevalence, positive and negative predictive value, false-positive, and false-negative results were calculated.

Results: In 3,709 singleton fetuses, KANET was assessed. Postnatal follow-up was available for 1,556 of 1,573 (42.4\%) infants. For 2,136, the data were not available. Interrater reliability ( $\mathrm{k}$ coefficient) for low-risk fetuses was between 0.64 and 0.65 (agreement $94.2-97.3 \%$ ), for high-risk fetuses was between 0.44 and 0.53 (agreement 70.5-78.9\%), respectively. Borderline KANET was found in $153(9.7 \%)$, abnormal in 52 (3.3\%), both more prevalent in high-risk pregnancies $\left(\chi^{2}=457.36 ; \mathrm{df}=2 ; p<0.01\right)$. Abnormal KANET was connected with severe postnatal developmental delay $\left(\chi^{2}=315.28 ; \mathrm{df}=6 ; p<0.01\right)$. In 47 out of 1,102 children aged 2 years and more, abnormal KANET was found, among them in one with CP. In 1 out of 1,055 children with normal KANET, severe developmental delay was found. The KANET has low sensitivity for detection of developmental delay and CP. The KANET specificity is high for all tested variables, positive predictive value and the false-positive rate are high, the negative predictive value is high (99.77-99.95\%), and the false-negative rate is low (0.23-0.05\%).
\end{abstract}

Conclusion: With normal KANET, there is a high probability of normal infant development. If the KANET score is borderline or abnormal in high-risk pregnancies, postnatal development may appear abnormal.

Keywords: Cerebral palsy, Development, Fetal behavior, Fetal neurology, Four-dimensional ultrasound, General movements.

Donald School Journal of Ultrasound in Obstetrics and Gynecology (2020): 10.5005/jp-journals-10009-1669

\section{INTRODUCTION}

After the first published assessment of the "developmental neurology of the fetus" using two-dimensional real-time ultrasound (2D US) by Prechtl and Visser at the end of the 1980s and the beginning of the $1990 \mathrm{~s}^{1,2}$ neurological assessment of the fetus has undergone many changes after the introduction of fourdimensional ultrasonography (4D US) and development of the Kurjak antenatal neurodevelopmental test (KANET). ${ }^{3}$ Prechtl and Visser by using 2D US and Kurjak by using 4D US were convinced that ultrasound opened up a new field of fetal neurology by the introduction of a standardized and comprehensive method to objectively and reproducibly evaluate the fetal neurological condition by observation of fetal behavior and general movements (GMs). ${ }^{1-5}$ However, it is not easy to make conclusions based only on the assessment of the fetal motoric function or even on the assessment of GMs, because, as can be learned from postnatal neurological assessment, it is much more complex. Namely, the components of postnatal neurological assessment include cognitive function, cranial nerves, motor strength, sensation, reflexes, coordination, and gait, while neurodevelopmental disorders affect emotion, learning, self-control, and memory. Besides that neurology uses many additional diagnostic tests including assessment of the structure (neuroimaging methods) and function (electroencephalography, electromyography, nerve conduction studies, and evoked potentials) to make a correct diagnosis, which is prerequisite for the proper treatment, counseling, and prevention. ${ }^{6-11}$ Although there has been an attempt to speculate about cognitive function of the fetus and
${ }^{1}$ Department of Obstetrics and Gynecology, Medical School University of Zagreb, Zagreb, Croatia; University Sarajevo School of Science and Technology, Sarajevo, Bosnia and Herzegovina

${ }^{2}$ Department of Obstetrics and Gynecology, Neonatal Unit, Medical School University of Zagreb, University Hospital Sveti Duh, Zagreb, Croatia

${ }^{3}$ Department of Obstetrics and Gynecology, Private Clinic Veritas, Zagreb, Croatia

${ }^{4}$ Department of Obstetrics and Gynecology, Alexandra Maternity Hospital, Medical School University of Athens, Athens, Greece; Department of Fetal Maternal Medicine, Alexandra Maternity Hospital, Medical School University of Athens, Athens, Greece

${ }^{5}$ Clinical Ultrasound and Fetal Medicine Unit - Ecomoinhos, Porto Alegre, Brazil

'Department of Infertility and IVF, Polyclinic "Korak do Života", Tuzla, Bosnia and Herzegovina

${ }^{7}$ Dr Nagori's Institute for Infertility and IVF, Ahmedabad, Gujarat, India

${ }^{8}$ Department of Obstetrics and Gynecology, Medical University of Warsaw, Warsaw, Poland

${ }^{9}$ Annai Velankanni Multispecialty Hospital, Palayamkottai, Tirunelveli, Tamil Nadu, India

${ }^{10}$ Department of Obstetrics and Gynecology, Perinatology Department, Baskent University Medical Faculty, Ankara, Turkey

${ }^{11}$ Clinic of Gynecology and Obstetrics, Clinical Center University of Sarajevo, and Department of Gynecology, School of Medicine, Sarajevo School of Science and Technology, Sarajevo, Bosnia and Herzegovina

${ }^{12}$ Department of Physiology, Medical School University of Zagreb, Zagreb, Croatia

() The Author(s). 2020 Open Access This article is distributed under the terms of the Creative Commons Attribution 4.0 International License (https://creativecommons. org/licenses/by-nc/4.0/), which permits unrestricted use, distribution, and non-commercial reproduction in any medium, provided you give appropriate credit to the original author(s) and the source, provide a link to the Creative Commons license, and indicate if changes were made. The Creative Commons Public Domain Dedication waiver (http://creativecommons.org/publicdomain/zero/1.0/) applies to the data made available in this article, unless otherwise stated. 
some principles of developmental neurology have been introduced to the field of fetal neurology, still ultrasound assessment cannot replace postnatal neurological assessment. ${ }^{12}$ The intrauterine watery environment of microgravity in which the fetus is developing is quite different from postnatal circumstances, which is making the neurological assessment of the fetus more complicated and complex. ${ }^{13,14}$ With the diagnosis of cerebral palsy (CP) in infancy before 6 months of age, there are even more controversies and unanswered questions. ${ }^{15}$

The paper aims to evaluate what has been achieved by the application of the KANET till now in multicentric international studies, and based on the conclusions, how to proceed with KANET application, or in other words, how should fetal neurology be developing in the future.

\section{Materials and Methods}

The questionnaire was sent to nine investigators using KANET. The investigators were asked the following questions: when did they start to use KANET; how many patients they investigated from the beginning of KANET use till the end of April 2020; how many of them were scored as normal, borderline, and abnormal; for how many patients postnatal follow-up was available; what were the results of postnatal follow-up in patients scored by KANET as normal, borderline, and abnormal? The children were followed by local health services and the parents were asked about the development of the children. In the case of developmental delay, the parents were asked to share the medical documentation concerning the medical condition of the child with the leader of the prenatal KANET assessment. The data from individual centers will be presented separately as well as aggregated data.

All investigators were trained for KANET by the same teacher, which is the reason to calculate interrater reliability and Cohen's $\mathrm{K}$ between investigator and all others separately for the low- and highrisk group using borderline and abnormal KANET scores summed, using automated calculator available at https://idostatistics.com/ cohen-kappa-free-calculator/\#risultati. The Chi-square test will be used to test the frequency of KANET scores from low- and high-risk pregnancies using contingency tables and automated calculator for Chi-square testing. ${ }^{16}$ The result will be considered as statistically significant if $p<0.05$ for a certain degree of freedom. Specificity, sensitivity, prevalence, positive and negative predictive value, false-positive, and false-negative results will be calculated by using the automated calculator available at https://www.graphpad.com/ quickcalcs/clinTest1/ (accessed on May 22, 2020). ${ }^{17}$ The KANET was described in detail elsewhere. ${ }^{18-22}$

\section{Results}

The results from all investigations are presented in Table 1, with the country of origin of the investigator, the month and the year of the introduction of KANET, with number of patients investigated till the end of April 2020, number of infants with postnatal follow-up, and number of fetuses with borderline and abnormal KANET scores. ${ }^{18-24}$ The investigators introduced KANET from May 2010 to July 2019, assessed altogether 3,709 fetuses from singleton pregnancies between 28 weeks and 36 weeks of gestation, with 1,573 (42.4\%) children available for postnatal follow-up, while for 2,136 mostly low-risk examinees the data were not available (2094 or $98.0 \%$ ) or the pregnancies are still ongoing (42 or $2.0 \%$ ). In the entire investigated group of 3,709 fetuses the number of borderline KANET scores was 379 (10.2\%), while in 124 (3.3\%) of the fetuses KANET was abnormal,
${ }^{13}$ Department of Preventive and Pediatric Dentistry, Public Health Center of Sarajevo Canton, Sarajevo, Bosnia and Herzegovina

${ }^{14}$ Department of Psychiatry, Medical School University of Zagreb, University Hospital Center Zagreb, Zagreb, Croatia

Corresponding Author: Asim Kurjak, Department of Obstetrics and Gynecology, Medical School University of Zagreb, Zagreb, Croatia; University Sarajevo School of Science and Technology, Sarajevo, Bosnia and Herzegovina, Phone: +385 91 4512096, e-mail: asim. kurjak1@yahoo.com

How to cite this article: Kurjak A, Stanojević $M$, Spalldi Barišić $L$, et al. A Critical Appraisal of Kurjak Antenatal Neurodevelopmental Test: Five Years of Wide Clinical Use. Donald School J Ultrasound Obstet Gynecol 2020;14(4):304-310.

Source of support: Nil

Conflict of interest: None

respectively. In the group of 1,573 fetuses who were eligible for postnatal follow-up, the number of borderline KANET scores was 153 (9.7\%) and the number of abnormal KANET scores was 52 (3.3\%).

The data on KANET scores according to the pregnancy risk are presented in Table 2. Out or 2,502 low-risk pregnancies, there were 2,357 normal, 145 borderline, and none abnormal KANET scores, while the number of high-risk pregnancies was 1,237 with 850 normal, 234 borderline, and 124 abnormal KANET scores. In high-risk pregnancies there was a higher frequency of borderline and especially abnormal KANET scores, which was statistically highly significant $\left(\chi^{2}=457.36 ; \mathrm{df}=2 ; p<0.01\right)$. Interrater reliability was calculated for low- and high-risk pregnancies separately for all investigators related to the results of Zagreb investigator. For low-risk pregnancies, the Cohen's kappa coefficient was between 0.64 and 0.65 (substantial agreement from 94.2 to $97.3 \%$ ), and for high-risk pregnancies kappa was between 0.44 and 0.53 (moderate agreement from 70.5 to $78.9 \%$ ).

Results after completed pregnancies and postnatal follow-up of children after KANET testing in low- and high-risk group are shown in Table 3. There were 1,573 (42.4\%) completed pregnancies after KANET in all groups. Intrauterine death or termination of pregnancy due to the lethal congenital malformation happened in 7 fetuses, while 10 of them died early in the postnatal period after being live-born. Severe congenital malformation was diagnosed in 17 fetuses and confirmed postnatally of which 15 were either terminated or died postnatally. Out of 1,573 fetuses, 1,566 (99.6\%) were live-born out of whom 10 died postnatally, meaning that 1,556 (98.9\%) children were available for postnatal evaluation. According to the age, there were 54 (3.5\%) infants below 6 months, 93 (6.0\%) between 6 months and 12 months, 297 (19.1\%) from 13 to 24 months, 283 (18.2\%) between 25 months and 36 months, and 819 (52.6\%) equal or more than 37 months. Normal development was noted in $1,530(98.3 \%)$ children, the slight developmental delay was found in $3(0.19 \%)$, moderate in $5(0.32 \%)$, and severe developmental delay in 18 (1.15\%) examinees. Out of those with a severe developmental delay, there was one infant older than 3 years who had abnormal KANET scores, diagnosed with CP, who had an older brother with $\mathrm{CP}$. One child who was 33 months old in whom KANET score was considered normal developed severe developmental delay and was diagnosed with Kagami Ogata syndrome. ${ }^{24}$

Postnatal follow-up of fetuses with borderline and abnormal KANET scores is presented in Table 4. There were 153 fetuses with borderline scores and 52 fetuses with abnormal KANET scores, of whom 11 were terminated in utero or died postnatally, meaning that 41 could be evaluated postnatally. In the group with borderline 
Table 1: Results of the KANET ${ }^{+}$test from nine centers: the date of the introduction of KANET, number of patients investigated, total number of borderline and abnormal scores, number with postnatal follow-up, number of borderline and abnormal cases in all fetuses and those postnatally followed up

\begin{tabular}{|c|c|c|c|c|c|c|c|}
\hline \multirow{3}{*}{$\begin{array}{l}\text { Name of the } \\
\text { investigator/ } \\
\text { country }\end{array}$} & \multirow{3}{*}{$\begin{array}{l}\text { Introduction of } \\
\mathrm{KANET}^{+}\end{array}$} & \multirow{3}{*}{$\begin{array}{l}\text { Number of } \\
\text { fetuses }\end{array}$} & \multirow{2}{*}{\multicolumn{2}{|c|}{$\begin{array}{c}\text { All fetuses } \\
K A N E T^{+} \text {scores }\end{array}$}} & \multicolumn{3}{|c|}{ Postnatal follow-up } \\
\hline & & & & & \multirow{2}{*}{$\begin{array}{l}\text { Number of } \\
\text { children }\end{array}$} & \multicolumn{2}{|c|}{$K^{\prime} A N E T^{+}$scores } \\
\hline & & & Borderline & Abnormal & & Borderline & Abnormal \\
\hline * & May, 2010 & 1344 & $98(7.3 \%)$ & $52(3.9 \%)$ & $482(35.9 \%)$ & $36(7.5 \%)$ & 19 (3.9\%) \\
\hline 19 & January, 2012 & 1180 & 105 (8.9\%) & $40(3.4 \%)$ & $520(44.1 \%)$ & 47 (9.0\%) & $19(3.7 \%)$ \\
\hline 20 & November, 2014 & 631 & $115(18.2 \%)$ & $19(3.0 \%)$ & $212(33.6 \%)$ & 39 (18.2\%) & $6(3.0 \%)$ \\
\hline 22 & May, 2015 & 141 & $38(27.0 \%)$ & $5(3.5 \%)$ & $60(42.6 \%)$ & $16(27.0 \%)$ & $2(3.5 \%)$ \\
\hline 22 & October, 2015 & 160 & $3(1.9 \%)$ & 0 & 145 (90.6\%) & $3(1.9 \%)$ & 0 \\
\hline 22 & July, 2017 & 63 & $6(9.5 \%)$ & $3(4.8 \%)$ & $26(41.3 \%)$ & $2(9.5 \%)$ & $1(4.8 \%)$ \\
\hline * & July, 2018 & 64 & 0 & $1(1.6 \%)$ & $35(54.7 \%)$ & 0 & $1(1.6 \%)$ \\
\hline 22 & February, 2019 & 25 & $4(16.0 \%)$ & $1(4.0 \%)$ & $17(68.0 \%)$ & $3(16.0 \%)$ & $1(4.0 \%)$ \\
\hline * & July, 2019 & 101 & 10 (9.9\%) & $3(3.0)$ & $76(75.2 \%)$ & $7(9.2 \%)$ & $3(3.9 \%)$ \\
\hline Total & $\begin{array}{l}\text { May, 2010-July, } \\
2019\end{array}$ & 3709 & $379(10.2 \%)$ & $124(3.3 \%)$ & 1573 (42.4\%) & $153(9.7 \%)$ & $52(3.3 \%)$ \\
\hline
\end{tabular}

${ }^{+}$KANET Kurjak antenatal neurodevelopmental test

*Unpublished data

Table 2: The data on KANET \& scores from low- and high-risk pregnancies shown as normal, borderline and abnormal, comparing abnormal and borderline score prevalence depending on the pregnancy risk

\begin{tabular}{|c|c|c|c|c|c|}
\hline \multirow{2}{*}{$\begin{array}{l}\text { Name of the investi- } \\
\text { gator }\end{array}$} & \multirow[b]{2}{*}{ Risk of the pregnancy } & \multicolumn{3}{|c|}{ KANET score } & \multirow[b]{2}{*}{ Total number } \\
\hline & & Normal & Borderline & Abnormal & \\
\hline \multirow[t]{2}{*}{$N^{*}=1344$} & Low & 1017 & 31 & 0 & 1048 \\
\hline & High & 177 & 67 & 52 & 296 \\
\hline \multirow[t]{2}{*}{$N=1180$} & Low & 772 & 23 & 0 & 795 \\
\hline & High & 263 & 82 & 40 & 385 \\
\hline \multirow[t]{2}{*}{$N=631$} & Low & 348 & 58 & 0 & 406 \\
\hline & High & 149 & 57 & 19 & 225 \\
\hline \multirow[t]{2}{*}{$N=141$} & Low & 96 & 33 & 0 & 129 \\
\hline & High & 2 & 5 & 5 & 12 \\
\hline$N=160$ & High & 157 & 3 & 0 & 160 \\
\hline \multirow[t]{2}{*}{$N=63$} & Low & 30 & 0 & 0 & 30 \\
\hline & High & 24 & 6 & 3 & 33 \\
\hline \multirow[t]{2}{*}{$N=64$} & Low & 30 & 0 & 0 & 30 \\
\hline & High & 33 & 0 & 1 & 34 \\
\hline$N=25$ & High & 20 & 4 & 1 & 25 \\
\hline \multirow[t]{2}{*}{$N=101$} & Low & 64 & 0 & 0 & 64 \\
\hline & High & 24 & 10 & 3 & 37 \\
\hline Subtotal low risk & & 2357 (94.2\%) & $145(5.8 \%)$ & 0 & 2502 (67.5\%) \\
\hline Subtotal high risk & & 849 (70.3\%) & 234 (19.4\%) & $124(10.3 \%)$ & 1207 (32.5\%) \\
\hline Total & & 3206 (86.5\%) & 379 (10.2\%) & $124(3.3 \%)$ & 3709 \\
\hline
\end{tabular}

$\chi^{2}=457.36 ; \mathrm{df}^{+}=2 ; p<0.01$

\&Kurjak antenatal neurodevelopmental test

${ }^{*} N=$ total number of pregnancies

${ }^{+} \mathrm{df}=$ degrees of freedom

KANET scores, there were 145 with normal postnatal development, 2 had moderate, and 4 had severe developmental delay, while two fetuses died in utero. In the group of 52 infants with abnormal KANET scores, 26 had normal development, 1 infant had slight developmental delay, 1 moderate, and 13 infants had severe developmental delay, while 11 died in utero. Severe developmental delay was more frequent in the group with abnormal KANET scores, which was highly statistically significant (Table $4 ; \chi^{2}=315.28 ; \mathrm{df}=6$; $p<0.01$ ). Out of 1,102 children older than 2 years, 36 had abnormal and 11 borderline KANET scores. Of 47 children with borderline abnormal KANET scores in one more than 3 years old child CP was diagnosed. Out of 1,556 children with normal KANET scores, 26 had developmental delay, of whom it appeared severe in 18. One child from that group who had a normal KANET score developed 


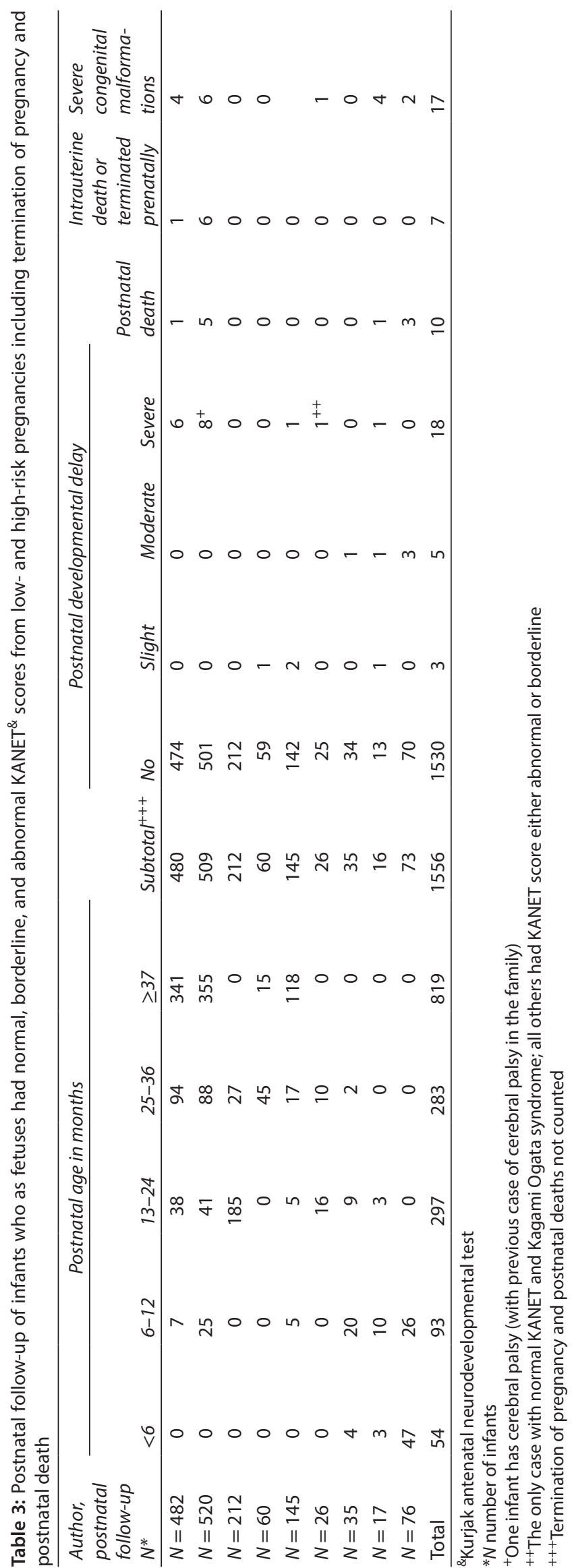

severe developmental delay due to Kagami Ogata syndrome and is now 33 months old. ${ }^{24}$

Table 5 presents predictive values from sensitivity, specificity, and prevalence in three groups of children with positive KANET scores. The first two groups are derived from the group of 192 children with borderline and abnormal KANET scores, 24 of whom were diagnosed with all stages of developmental delay regardless of the age, and 18 children had severe developmental delays regardless of their age. The third group was represented by 1,102 children more than 2 years of age of whom one with positive KANET scores out of 47 developed CP, and one who developed severe developmental delay from the same group had normal KANET score. Sensitivity, specificity, prevalence, positive and negative predictive value, false-positive, and false-negative rates are presented in Table 5.

\section{Discussion}

The data of fetal prenatal neurological testing from nine centers by nine investigators from seven countries which were performed from May 2010 to April, 2020, with the number of 25-1,344 fetuses from singleton pregnancies are presented in the paper. Altogether there were 3,709 fetuses of whom 1,573 (42.4\%) completed the pregnancy of which 1,556 were eligible for postnatal follow-up, while in 2,136 mostly low-risk pregnancies for 2,094 the data were missing while in 42 the pregnancies were still ongoing (Table 1). From the group of 3,709 fetuses, 3,206 (86.5\%) had normal, 379 (10.2\%) borderline, and 124 (3.3\%) abnormal KANET scores, respectively, while in those after completed pregnancy 153 (9.7\%) had borderline and 52 (3.3\%) had abnormal KANET scores (Tables 1 and 2). The interrater reliability was substantial for low-risk pregnancies and moderate for highrisk pregnancies. There were 2,502 (67.5\%) fetuses from low-risk pregnancies and 1,207 (32.5\%) fetuses from high-risk pregnancies (Table 2). Fetuses from high-risk pregnancies had higher frequencies of borderline and abnormal KANET scores compared to the fetuses from low-risk pregnancies, which was statistically significant. It could be speculated that a hostile intrauterine environment is affecting adversely fetal neurobehavior, which can be detected by the KANET. The dropout rate in the investigation was high (47.6\%), respectively, which is a severe constraint of the investigation. Most of the dropouts were from the low-risk pregnancies with low rates of borderline or abnormal KANET scores and high probability of normal postnatal development.

Out of 1,556 fetuses who were born after KANET testing, the distribution based on age is presented in Table 3. Most of the children were older than 3 years (819 out of 1,556 or $52.6 \%$ ). Most of the infants were developing normally (1,530 or $98.3 \%), 8$ $(0.5 \%)$ had slight and moderate developmental delay, while 18 (1.2\%) had severe developmental delay. The severe and moderate developmental delay could develop more frequently in the group of infants who as fetuses had abnormal KANET scores, which are presented in Table 4, which was statistically significant. Most of the infants with abnormal KANET scores were from highrisk pregnancies, had severe congenital malformations, often intrauterine growth restriction (IUGR), and had more chance to die in utero. To investigate the validity of the KANET for the prediction of developmental delay and $\mathrm{CP}$, we made predictive value calculations from sensitivity, specificity, and prevalence for all age groups with developmental delay and only for the age group above 2 years for the CP and severe developmental delay. The calculations showed that the KANET has low sensitivity for 
Table 4: Postnatal follow-up of infants who as fetuses had borderline and abnormal KANET ${ }^{\&}$ scores from low- and high-risk pregnancies including termination of pregnancy and postnatal death

\begin{tabular}{|c|c|c|c|c|c|c|}
\hline \multirow{2}{*}{$\begin{array}{l}\text { Name of the inves- } \\
\text { tigator }\left(N^{*}\right)\end{array}$} & \multirow[b]{2}{*}{ KANET score $\left(N^{*}\right)$} & \multicolumn{4}{|c|}{ Postnatal developmental delay $\left(N^{*}\right)$} & \multirow[b]{2}{*}{ Comment } \\
\hline & & No & Slight & Moderate & Severe & \\
\hline \multirow[t]{2}{*}{$N=482$} & Borderline $N=36$ & 33 & 0 & 0 & 2 & 1 IUD $^{+}$ \\
\hline & Abnormal $N=19$ & 15 & 0 & 0 & 4 & $\begin{array}{l}\text { All severe congenital } \\
\text { malformations }\end{array}$ \\
\hline \multirow[t]{2}{*}{$N=520$} & Borderline $N=47$ & 45 & 0 & 0 & 1 & 1 IUD $^{+}$ \\
\hline & Abnormal $N=19$ & 7 & 0 & 0 & $1^{++}$ & 5 died, 6 terminated \\
\hline \multirow[t]{2}{*}{$N=212$} & Borderline $N=39$ & 39 & 0 & 0 & 0 & - \\
\hline & Abnormal $N=6$ & 3 & 0 & 0 & 3 & $\begin{array}{l}\text { One case of trisomy } 13,18 \text {, and } \\
21\end{array}$ \\
\hline \multirow[t]{2}{*}{$N=60$} & Borderline $N=16$ & 16 & 0 & 0 & 0 & - \\
\hline & Abnormal $N=2$ & 1 & 1 & 0 & 0 & $\begin{array}{l}\text { IUGR** one with slight } \\
\text { developmental delay }\end{array}$ \\
\hline \multirow[t]{2}{*}{$N=145$} & Borderline $N=3$ & 0 & 0 & 2 & 1 & - \\
\hline & Abnormal $N=0$ & 0 & 0 & 0 & 0 & - \\
\hline \multirow[t]{2}{*}{$N=26$} & Borderline $N=2$ & 2 & 0 & 0 & 0 & - \\
\hline & Abnormal $N=1$ & 0 & 0 & 0 & 1 & $\begin{array}{l}\text { One with severe delay Kagami } \\
\text { Ogata syndrome }\end{array}$ \\
\hline \multirow[t]{2}{*}{$N=35$} & Borderline $N=0$ & 0 & 0 & 0 & 0 & - \\
\hline & Abnormal $N=1$ & 0 & 0 & 1 & 0 & IUGR** \\
\hline \multirow[t]{2}{*}{$N=17$} & Borderline $N=3$ & 3 & 0 & 0 & 0 & - \\
\hline & Abnormal $N=1$ & 0 & 0 & 0 & 1 & $\begin{array}{l}\text { Trisomy } 18 \text {, died in the } 1 \text { st day } \\
\text { of life }\end{array}$ \\
\hline \multirow[t]{2}{*}{$N=76$} & Borderline $N=7$ & 7 & 0 & 0 & 0 & - \\
\hline & Abnormal $N=3$ & 3 & 0 & 0 & 3 & $\begin{array}{l}2 \text { severe congenital } \\
\text { malformations and one IUGR** }\end{array}$ \\
\hline $\begin{array}{l}\text { Subtotal normal } \\
\text { KANET }\end{array}$ & 1351 (86.8\%) & $1348(99.8)$ & 0 & $2(0.1 \%)$ & $1(0.1 \%)$ & $\begin{array}{l}\text { One with severe delay Kagami } \\
\text { Ogata syndrome }\end{array}$ \\
\hline $\begin{array}{l}\text { Subtotal } \\
\text { borderline KANET }\end{array}$ & 153 (9.8\%) & 145 (94.8\%) & 0 & $2(1.3 \%)$ & $4(2.6 \%)$ & 2 IUD (1.3\%) \\
\hline $\begin{array}{l}\text { Subtotal abnormal } \\
\text { KANET }\end{array}$ & $52(3.3 \%)$ & $26(50.0 \%)$ & $1(1.9 \%)$ & $1(1.9 \%)$ & $\begin{array}{l}13 \\
(25.0 \%)\end{array}$ & 11 terminated or died (21.2\%) \\
\hline Total & $1556(100.0 \%)$ & $1519(97.6 \%)$ & $1(0.1 \%)$ & $5(0.3 \%)$ & $18(1.2 \%)$ & $13(0.8 \%)$ \\
\hline $\begin{array}{l}\chi^{2}=315.28 ; \mathrm{df}^{+++}=6 \\
{ }^{8} \text { Kurjak antenatal neu } \\
{ }^{*} \mathrm{~N} \text { number of infants } \\
{ }^{+} \text {IUD intrauterine dea } \\
++ \text { One infant with CP } \\
{ }^{* *} \text { IUGR intrauterine } \mathrm{g} \\
{ }^{+++} \mathrm{df}=\text { degrees of fre }\end{array}$ & $\begin{array}{l}\text { p } p<0.01 \\
\text { rodevelopmental te } \\
\text { th } \\
\text { (with previous case } \\
\text { rowth restriction } \\
\text { eedom }\end{array}$ & cerebral palsy & amily) & & & \\
\hline
\end{tabular}

the detection CP and lower sensitivity for the detection of slight, moderate, and severe developmental delay, than for only severe developmental delay. Specificity was rather high for detection of CP; it was lower for the detection of developmental delay. In concordance, positive predictive value and the false-positive rate were high. The negative predictive value was high and the falsenegative rate was low. If the KANET score is normal, then there is a huge probability of postnatal normal development, with a very small chance that it is false-negative meaning that the probability of abnormal postnatal development is low if KANET was normal. There is a problem with the interpretation of abnormal and borderline KANET scores, which appears to have very low sensitivity and positive predictive value and high false-positive rate. This means that based on the borderline or abnormal KANET score one cannot predict the neurodevelopmental outcome, although there is a higher tendency of developmental disorders to occur in infants with abnormal KANET scores from high-risk pregnancies; however it cannot be concluded concerning the type and severity of the disorder, especially not CP. As it has been pointed out many times in the papers published up to now by our team, the most important aim of KANET introduction was to early predict the development of CP in order to intervene early enough to decrease possible consequences of the condition on individual, family, societal, and public health level. We were aware that early diagnosis of $\mathrm{CP}$ was and is not easy even postnatally. There is a rule saying that making the diagnosis of CP is inversely proportional to the age, undermining confidence in diagnosing $\mathrm{CP}$ early. Possible barriers in postnatal early diagnosis could be: $:^{25}$ 
Table 5: Predictive values from sensitivity, specificity, and prevalence for all age groups of infants with developmental delay, those with severe developmental delay, and those older than 2 years with a proved diagnosis of cerebral palsy who had abnormal and borderline KANET test prenatally (data derived from the Table 4)

\begin{tabular}{|c|c|c|c|}
\hline \multirow[b]{3}{*}{ Parameter } & \multicolumn{3}{|c|}{ Borderline and abnormal KANET score } \\
\hline & \multicolumn{2}{|c|}{ Developmental delay (all ages) N=192 } & \multirow{2}{*}{$\begin{array}{l}\text { Above } 2 \text { years } N=47 \\
\text { Severe developmental delay and } C P \\
N=2\end{array}$} \\
\hline & $\begin{array}{l}\text { Slight, moderate, and } \\
\text { severe } N^{\&}=24\end{array}$ & $\begin{array}{l}\text { Only severe } \\
N^{\&}=18\end{array}$ & \\
\hline Number of true-positive & 21 & 17 & 1 \\
\hline Number of false-positive & 171 & 175 & 46 \\
\hline Number of true-negative & 1,348 & 1,350 & 1,101 \\
\hline Number of false-negative & 3 & $1^{*}$ & $1^{* *}$ \\
\hline Sensitivity & $87.50 \%$ & $94.44 \%$ & $50 \%$ \\
\hline Specificity & $88.74 \%$ & $88.53 \%$ & $95.99 \%$ \\
\hline Prevalence & $1.6 \%$ & $1.2 \%$ & $0.09 \%$ \\
\hline Positive predictive value & $11.22 \%$ & $9.09 \%$ & $1.11 \%$ \\
\hline False-positive rate & $88.78 \%$ & $90.91 \%$ & $98.89 \%$ \\
\hline Negative predictive value & $99.77 \%$ & $99.92 \%$ & $99.95 \%$ \\
\hline False-negative rate & $0.23 \%$ & $0.08 \%$ & $0.05 \%$ \\
\hline
\end{tabular}

- There are no clinical signs on the clinical examination, which can confirm or rule out the diagnosis.

- High probability of false-positive diagnosis.

- Lack of specific biomarkers, genetic, or other tests helpful in making the diagnosis.

- Due to grief and the stigma of the family with the child diagnosed with $C P$, there is the desire of the healthcare providers to rule out every treatable condition first by wide differential diagnosis.

- There are no curative treatments and evidence of the efficacy of the early intervention is scarce.

Another important recurrent discussion lasting for decades on $\mathrm{CP}$ is when the earliest diagnosis of CP could be made to avoid the development of deformities connected with the disease. ${ }^{25}$ For many years from the 1970s, it is accepted that it is almost impossible to make the diagnosis of CP in infancy, and that acceptable age for the diagnosis is between 3 years and 5 years. ${ }^{25} \mathrm{It}$ has been claimed that in a well-developed healthcare system the diagnosis of CP could be made in one of five children at the age of 6 months and in more than half of the cases after the first year of life. ${ }^{25}$ There is a belief that $C P$ is neurologically silent in the first few months of age and almost impossible to be diagnosed, which was the reason for the development of the concept of GMs by Prechtl et al., which enabled detection of neurological impairment by the recording of GMs by a camera and assessing them offline. The assessment was timeconsuming and not practical or clinically applicable for everyday clinical practice. However, in the recently published guidelines for the early diagnosis (by the age of 5 months in high-risk infants) of $\mathrm{CP}$, the following criteria have been mentioned: ${ }^{15}$

- $\mathrm{GM}$ assessment [sensitivity $98 \%$ (95\% Cl 74-100\%); specificity $91 \%(95 \% \mathrm{Cl} 83-93 \%)]$ at fidgety age, ${ }^{26}$

- Magnetic resonance imaging (MRI) at term equivalent age (sensitivity $86-100 \%$, specificity $89-97 \%$ ), and

- Hammersmith Infant Neurological Examination (HINE) (sensitivity at 3 months $96 \%$, specificity $85 \%$, Cl not reported). ${ }^{27}$
Mentioned criteria are aimed for high-risk infants, while infants with $\mathrm{CP}$ who do not have newborn detectable risks, and are seemingly healthy at birth, are less likely to be followed up, and there is a need for identifying these infants and administering best practice tools in order not to miss the diagnosis of $\mathrm{CP}$, which is nowadays in low-risk population very often overlooked and missed. ${ }^{25}$ For such term and high-risk preterm infants, automated computer-assisted/smartphone GMs assessment tool is under development, ${ }^{28}$ which will make a time-consuming assessment of GMs more practical, standardized, and clinically applicable.

We are aware of weaknesses of our study: nine investigators included high dropout rate, heterogeneity of the investigation group in terms of nationality and race, inhomogeneous groups of pregnant women in terms of risk of pregnancy, social status, age, parity, and many other characteristics. Although KANET was standardized and it was advised to be used in everyday clinical practice, it would be much better if all those weaknesses could have been avoided. ${ }^{29,30}$ The main weakness of the investigation is the postnatal follow-up of infants, which was dependent on local circumstances, and the information for infants who had developmental delays has been obtained from the parents and available medical charts. Such an approach may cause that some children with developmental delay may have been missed, without awareness of the investigator(s). That is why the results of the study should be taken with due caution.

\section{Conclusion}

Based on the results of the study, we can conclude that if the KANET score is normal then there is a high probability that the development of the infant will be normal, with a very low probability that the child with developmental delay would have been missed. However, if the KANET score is borderline and especially if abnormal in high-risk pregnancy, postnatal development of the child may appear abnormal. Due to a high false-positive rate in those fetuses, 
thorough postnatal prospective neurodevelopmental follow-up especially in high-risk infants with a positive family history on CP should be advised. ${ }^{25}$ To make an early diagnosis of CP in high-risk cases, the protocol proposed by Novak et al. should be followed, ${ }^{25}$ while for low-risk infants with abnormal KANET scores the protocol should be individualized and follow-up established on a case-bycase basis. The future development of fetal neurology should be multidisciplinary with special emphasis on scrutinized postnatal follow-up of infants who had abnormal and borderline KANET scores and were born from high-risk pregnancies.

\section{References}

1. Prechtl HF. Developmental neurology of the fetus. Baillieres Clin Obstet Gynaecol 1988;2(1):21-36. DOI: 10.1016/S0950-3552(88)800610.

2. Visser GH, Mulder EJ, Prechtl HF. Studies on developmental neurology in the human fetus. Dev Pharmacol Ther 1992;18(3-4):175-183. DOI: 10.1159/000480620.

3. Kurjak A, Miskovic B, Stanojevic M, et al. New scoring system for fetal neurobehavior assessed by three- and four-dimensional sonography. J Perinat Med 2008;36(1):73-181. DOI: 10.1515/JPM.2008.007.

4. Kurjak A, Stanojević $M$, Predojević $M$, et al. Neurobehavior in fetal life. Semin Fetal Neonat M 2012;17(6):319-323. DOI: 10.1016/j. siny.2012.06.005

5. Kurjak A, Antsaklis P, Stanojevic M. Fetal neurology: past present and future. Donald School J Ultrasound Obstet Gynecol 2015;9(1):6-29. DOI: 10.5005/jp-journals-10009-1385.

6. Ismail FY, Shapiro BK. What are neurodevelopmental disorders? Curr Opin Neurol 2019;32(4):611-616. DOI: 10.1097/ WCO.0000000000000710.

7. Patel DR, Merrick J. Neurodevelopmental and neurobehavioral disorders. Transl Pediatr 2020;9(Suppl 1):S1-S2. DOI: 10.21037/ tp.2020.02.03.

8. Smyth CN, Farrow JL. Present place in obstetrics for foetal phonocardiography and electrocardiography with the newer techniques of foetal electroencephalography and movementrecording. Br Med J 1958;2(5103):1005-1009. DOI: 10.1136/ bmj.2.5103.1005.

9. Sherman DJ, Ross MG, Day L, et al. Fetal swallowing: correlation of electromyography and esophageal fluid flow. Am J Physiol 1990;258(6 Pt 2):R1386-R1394. DOI: 10.1152/ajpregu.1990.258.6.R1386.

10. Dubois J, Adibpour P, Poupon C, et al. MRI and M/EEG studies of the white matter development in human fetuses and Infants: review and opinion. Brain Plast 2016;2(1):49-69. DOI: 10.3233/BPL-160031.

11. Ouyang $M$, Dubois J, Yu Q, et al. Delineation of early brain development from fetuses to infants with diffusion MRI and beyond. Neuroimage 2019;185:836-850. DOI: 10.1016/j.neuroimage.2018.04.017.

12. Salihagic Kadic A, Kurjak A. Cognitive functions of the fetus. Ultraschall in Med 2018;39(2):181-189. DOI: 10.1055/s-0043-123469.

13. Stanojevic M, Zaputovic S, Pavicic, et al. Continuity between fetal and neonatal neurobehavior. Semin Fetal Neonat M 2012;17(6):324-329. DOI: $10.1016 / j . \sin y .2012 .06 .006$.

14. Stanojevic M. Antenatal and postnatal assessment of neurobehavior: which one should be used? Donald School J Ultrasound Obstet
Gynecol 2015;9(1):67-74. DOI: 10.5005/jp-journals-100091391.

15. Novak I, Morgan C, Adde L, et al. Early, accurate diagnosis and early intervention in cerebral palsy: advances in diagnosis and treatment. JAMA Pediatr 2017;171(9):897-900. DOI: 10.1001/ jamapediatrics.2017.1689.

16. https://www.icalcu.com/stat/chisqtest.html (Accessed on May 22, 2020).

17. https://www.graphpad.com/quickcalcs/clinTest1/. (Accessed on May $22,2020)$.

18. Spalldi Barišić $L$, Kurjak A. Fetal neurobehavioral development in twin pregnancies Wataganara T, Kimata Pooh R, Kurjak A, ed. Donald School Textbook of PowerPoint Presentation on Advanced Ultrasound in Obstetrics and Gynecology. New Delhi: Jaypee Brothers Medical Publishers; 2016. pp.63-67. DOI: 10.5005/jp/books/12692_11.

19. Antsaklis $P$, Porovic $S$, Daskalakis $G$, et al. $4 D$ assessment of fetal brain function in diabetic patients. J Perinat Med 2017;45(6):711-715. DOI: 10.1515/jpm-2016-0394.

20. Stanojevic M, Moreira Neto R, Gaber G, et al. Clinical study of fetal neurobehavior by the Kurjak antenatal developmental test. Donald School J Ultrasound Obstet Gynecol 2017;11(4):355-361. DOI: 10.5005/ jp-journals-10009-1543.

21. Kurjak $A$, Antsaklis $P$, Stanojevic $M$, et al. Multicentric studies of the fetal neurobehavior by KANET test. J Perinat Med 2017;45(6):717-727. DOI: 10.1515/jpm-2016-0409.

22. Kurjak A, Spalldi Barišić $L$, Stanojević $M$, et al. Multi-center results on the clinical use of KANET. J Perinat Med 2019;47(9):897-909. DOI: 10.1515/jpm-2019-0281.

23. Tan KH, Smyth RMD, Wei X. Fetal vibroacoustic stimulation for facilitation of tests of fetal wellbeing. Cochrane Database Syst Rev 2013;12:CD002963. DOI: 10.1002/14651858.CD002963.pub2.

24. Huang H, Mikami Y, Shigematsu K, et al. Kagami-Ogata syndrome in a fetus presenting with polyhydramnios, malformations, and preterm delivery: a case report. J Med Case Rep 2019;13(1):340. DOI: 10.1186/ s13256-019-2298-y.

25. Velde A, Morgan C, Novak I, et al. Early diagnosis and classification of cerebral palsy: an historical perspective and barriers to an early diagnosis. J Clin Med 2019;8(10):1599. DOI: 10.3390/jcm8101599.

26. Bosanquet $\mathrm{M}$, Copeland $\mathrm{L}$, Ware $\mathrm{R}$, et al. A systematic review of tests to predict cerebral palsy in young children. Dev Med Child Neurol 2013;55(5):418-426. DOI: 10.1111/dmcn.12140.

27. Romeo DMM, Cioni M, Palermo F, et al. Neurological assessment in infants discharged from a neonatal intensive care unit. Eur J Paediatr Neurol 2013;17(2):192-198. DOI: 10.1016/j.ejpn.2012.09.006.

28. Kwong AK, Eeles AL, Olsen JE, et al. The baby moves smartphone app for general movements assessment: engagement amongst extremely preterm and term-born infants in a state-wide geographical study. J Paediatr Child Health 2019;55(5):548-554. DOI: 10.1111/jpc.14240.

29. Predojevic M, Miskovic B, Ahmed B, et al. An attempt to standardize Kurjak's antenatal neurodevelopmental test: osaka consensus statement. Donald School J Ultrasound Obstet Gynecol 2011;5(4):317329. DOI: 10.5005/jp-journals-10009-1209.

30. Predojevic M, Vladareanu $R$, Antsaklis $P$, et al. Is Kurjak antenatal neurodevelopmental test ready for routine clinical application: bucharest consensus statement. Donald School J Ultrasound Obstet Gynecol 2015;9(3):260-265. DOI: 10.5005/jp.journals-100009-1412. 